\title{
Calcium reduces vitamin D and glucocorticoid receptors in the visceral fat of obese male rats
}

\author{
E P S Conceição', E G Moura', A C Manhães², J C Carvalho', J L Nobre', \\ E Oliveira' and P C Lisboa'
}

1Laboratory of Endocrine Physiology, Department of Physiological Sciences, Roberto Alcantara Gomes Biology Institute, State University of Rio de Janeiro, Rio de Janeiro, Brazil

2Laboratory of Neurophysiology, Department of Physiological Sciences, Roberto Alcantara Gomes

Biology Institute, State University of Rio de Janeiro, Rio de Janeiro, Brazil

Correspondence

should be addressed

to P C Lisboa

Email

pclisboa@uerj.br

\begin{abstract}
Rats overfed during lactation show higher visceral adipose tissue (VAT) mass and metabolic dysfunctions at adulthood. As both vitamin $D$ and glucocorticoids change adipogenesis, parameters related to metabolism and action of these hormones in the adipocyte can be altered in rats raised in small litters (SL). We also studied the antiobesity effects of high calcium diet since it decreases visceral fat in obesity models. On postnatal day (PN) 3, litter size was adjusted to 3 pups/dam (SL) to induce overfeeding. Control litters (NL) remained with 10 pups/dam until weaning. From PN120 to PN180, half of the SL rats were fed standard chow (SL) and the other half was fed a calcium-supplemented chow (SL-Ca, $10 \mathrm{~g} \mathrm{CaCO}_{3} / \mathrm{kg}$ ). Both SL groups were heavier and hyperphagic when compared with the NL group; however, SL-Ca rats ate less than SL. SL-Ca rats had decreased VAT mass and adipocyte size, associated with lower hypothalamic NPY content, VAT fat acid synthase content and leptinemia. At PN120, SL rats had increased plasma 25(OH)D3, Cyp27b1 mRNA and glucocorticoid receptor $(G R-\alpha)$ in the VAT, but lower vitamin D receptor (Vdr) mRNA. At PN180, Cyp27b1 and GR- $\alpha$ remained higher, while $V d r$ normalized in SL rats. SL-Ca rats had normal VAT Cyp27b1 and GR- $\alpha$, but lower Vdr. Thus, higher body mass and glucocorticoid receptors in the VAT of SL rats are normalized by calcium-enriched diet, and Vdr expression in this tissue is reduced, suggesting a possible role of glucocorticoids and vitamin $D$ in calcium action in the adipocyte.
\end{abstract}

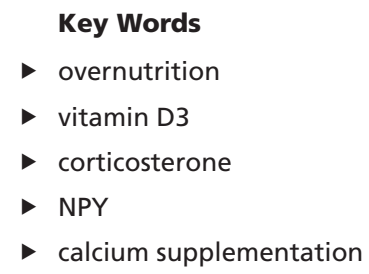

Journal of Endocrinology

(2016) 230, 263-274

\section{Introduction}

Overweight and obesity are a major public health concern, with social and economic implications (Finkelstein 2014). Both hypertrophy and hyperplasia of the adipose tissue, mainly in the visceral depot, are associated with high cardiovascular risk, dyslipidemia, diabetes and neoplasia, among other diseases (Cornier et al. 2008, Akbaraly et al. 2010). Several studies have been dedicated to the elucidation of the pathophysiology of obesity development as well as to the identification of potential therapies (Crane et al. 2015, Yao et al. 2015, Maksimov et al. 2016).

Obesity is related, either as a cause or as a consequence, to the disruption of several hormonal

Published by Bioscientifica Ltd 
systems. Higher levels of glucocorticoids (GCs) and/or increased tissue sensitivity to these hormones have proadipogenic and lipogenic actions (John et al. 2016). Chronic GC exposure results in preadipocyte differentiation, lipogenesis and insulin resistance (Yu et al. 2014, de Guia \& Herzig 2015). Conversely, some studies have shown that, despite the classical role of vitamin D on bone metabolism, this hormone has nonclassic functions in inflammatory pathways, cellular proliferation and differentiation (Omdahl et al. 2002), as well as in adipocyte metabolism, being involved in obesity development (Shi et al. 2001, Ghali et al. 2015). In fact, some studies have demonstrated a correlation between low levels of vitamin D and reduced calcium intake with increased body mass (Marotte et al. 2014, Yao et al. 2015).
Conversely, in an obese rat model, our group evidenced a higher serum level of the prohormone $25(\mathrm{OH}) \mathrm{D}$, which best represents the vitamin D status (Holick 2009, Briot et al. 2009, Glendenning 2015, Souberbielle et al. 2016). This finding was associated with higher CYP27B1 in the visceral adipocyte (the enzyme that activates $25(\mathrm{OH}) \mathrm{D}$ to $\left.1,25(\mathrm{OH})_{2} \mathrm{D}\right)$ and with lower vitamin $\mathrm{D}$ receptor (VDR) content, which could indicate a vitamin $\mathrm{D}$ resistance in the adipocyte level (Nobre et al. 2012, 2016). In addition, Malloy \& Feldman (2013) showed that VDR, in the absence of the ligand, inhibits UCP1 expression in human brown adipocytes, suggesting a reduced thermogenic capacity in vitamin D deficiency. Taken together, these observations would seem to indicate that the excess of GC action and the lack of vitamin D action are obesogenic.
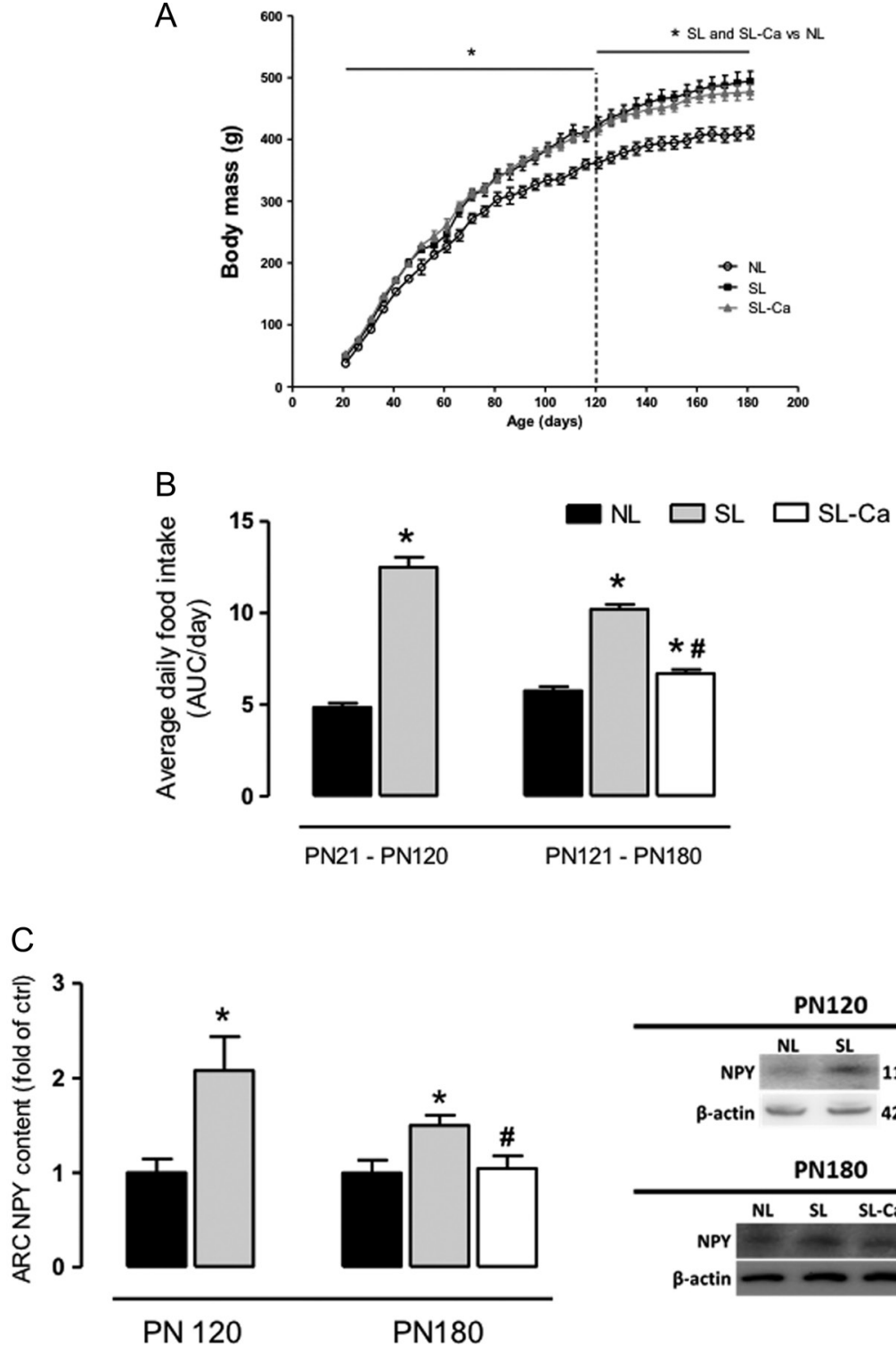

http://joe.endocrinology-journals.org DOI: 10.1530/JOE-16-0041
(C) 2016 Society for Endocrinology Printed in Great Britain
Figure 1

Effects on the body mass, food consumption and NPY content of postnatal early overnutrition followed by 2 months of dietary calcium supplementation at adulthood in Wistar rats. (A) Body mass from PN21 to PN180. (B) Average daily food intake per rat at PN120 and PN180. AUC, area under the curve (C) Neuropeptide $Y$ (NPY) protein content in the arcuate nucleus (ARC). Representative blots are shown next to the graph. $\beta$-actin content was used as control loading. Results are expressed as relative (\%) to the control. NL, normal litter group; SL, small litter group; SL-Ca, SL group that received calcium supplementation. The values represent mean \pm S.E.M. of 10 rats per group. ${ }^{*} P<0.05$ vs NL; $\# P<0.05$ vs SL. 
Rosenstreich and coworkers (1971) demonstrated that vitamin $\mathrm{D}$ is kept in high concentration in the adipose tissue due to its lipophilic characteristics. Vitamin D sequestration may influence fat tissue metabolism since adipocytes express the enzyme CYP27B1 and VDR (Omdahl et al. 2002). In fact, some studies indicate that vitamin $\mathrm{D}$ has a direct antiproliferative effect and decreases the adipogenesis process (Blumberg et al. 2006, Kong \& Li 2006, Shannan et al. 2007). Conversely, Sun and Zemel (2008) demonstrated that $1,25(\mathrm{OH})_{2} \mathrm{D}$ increases 11B-hydroxysteroid dehydrogenase 1 (11BHSD1) mRNA levels in the adipose tissue. This enzyme converts 11-dehydrocorticosterone into the active hormone corticosterone in order to supply local demand, and is frequently associated with increased adipogenesis (Ghali et al. 2015). Vitamin D also enhances GC receptor activation (Zhang et al. 2014). Thus, vitamin D can increases both GC production and action. Concerning GC, it has been demonstrated that dexamethasone treatment increases VDR expression in different cell types (Hidalgo et al. 2010), including adipocytes (Sun \& Zemel 2008). Therefore, both hormones can differentially influence the adipogenic process and play complementary roles.

The small litter (SL) size in rodents is an experimental model often used to study the long-term effects of precocious obesity. This manipulation causes persistent hyperphagia and higher visceral adiposity, as well as other important metabolic disorders (Habbout et al. 2013). Previously, Rodrigues and coworkers (2007) have shown a reduction in insulin signaling and glucose uptake in adult SL-rat adipocytes. Furthermore, we have also shown that SL rats, at adulthood, have adipocyte hypertrophy, despite the fact that they also have a normal circulating leptin concentration (Conceição et al. 2011). In the current study, we hypothesized that the metabolism and receptors of vitamin $\mathrm{D}$ and glucocorticoids in the adipocyte are altered in the obese SL rats, in spite of the normal circulating levels of both hormones (Conceição et al. 2013, de Albuquerque Maia et al. 2014), a possibility that could be associated with their obesity.

Previous data from our group have demonstrated that a calcium-supplemented diet is able to decrease visceral adiposity and 25(OH)D levels in two obesity models (early weaning and postnatal nicotine exposure), which can be associated (Nobre etal. 2012, 2016) or not (Nobre etal.2011) with reduction in food intake. These data lend support to the notion that dietary calcium supplementation can have beneficial effects on adipose tissue through changes in GC and vitamin D metabolism and receptors function. Thus, we also decided to investigate if dietary calcium supplementation can be useful to correct the adipocyte dysfunction observed in the SL model.

\section{Materials and methods}

\section{Experimental model}

The Animal Care and Use Committee of the Biology Institute of the State University of Rio de Janeiro approved our experimental protocol in accordance with the principles established in the Brazilian Law no. $11.794 / 2008$. Experiments were conducted following the ethical doctrine of the three ' $\mathrm{R}$ 's, reduction, refinement and replacement, to minimize the number of animals and the suffering caused by the experimental procedures.

Wistar rats (Rattus norvegicus) were housed in a temperature-controlled $\left(23 \pm 1^{\circ} \mathrm{C}\right)$ vivarium, on a $12 \mathrm{~h}$ light:12 h darkness cycle (lights on at 09:00 h), with free access to water and food. Thirty nulliparous female rats

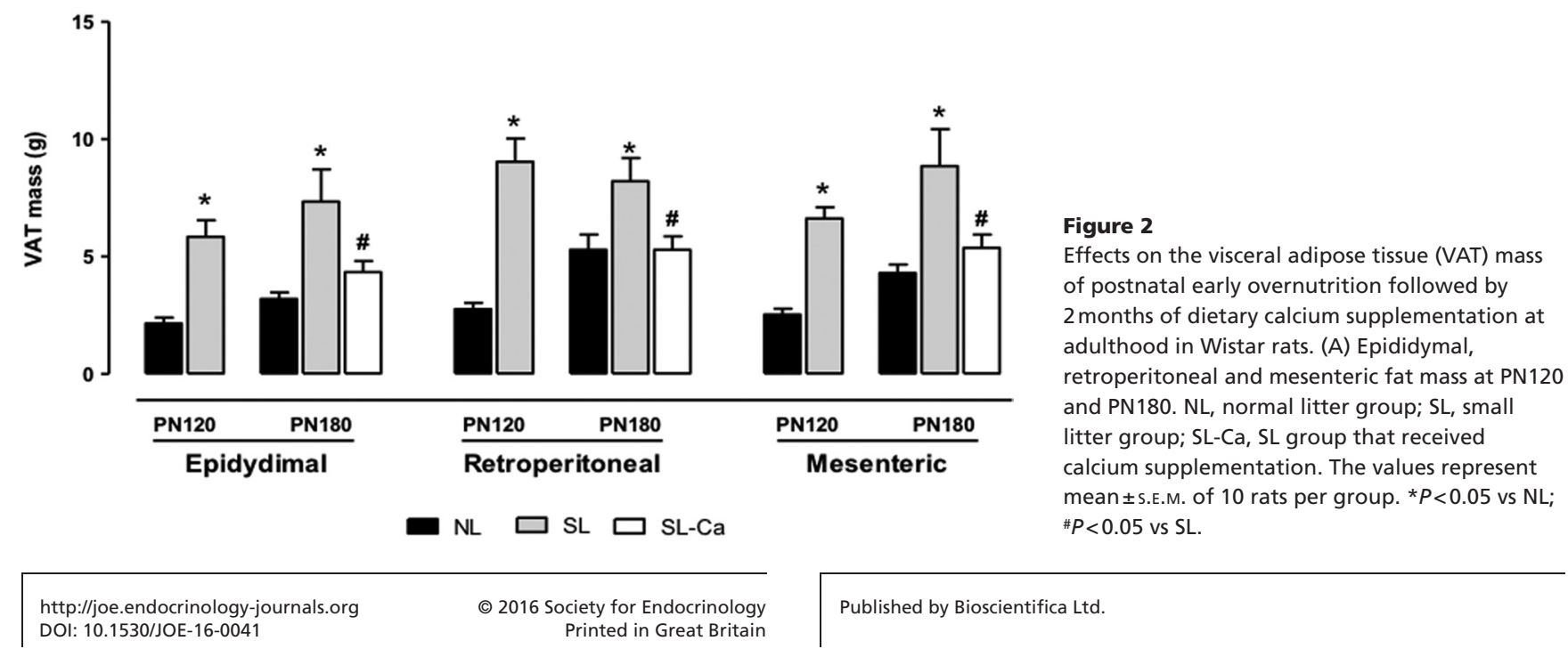


were placed with male rats (4 months old) in a 2 to 1 ratio for 5 days. The pregnant females were housed in individual cages until delivery. After birth (considered as the first postnatal day, PN1), all litters were adjusted to 10 male pups per dam. Only litters with 10 or more pups were used. To achieve 10 male pups per litter, when necessary, females were replaced by males from other litters at birth.

On PN3, to induce early overfeeding (SL), the litter size was reduced to 3 male pups per dam (number of litters $=15)$. The control group (NL, number of litters $=15$ ) was kept with 10 male pups per dam until weaning (PN21). After weaning, food intake and body mass were recorded until PN180 every 4 days. During the entire experimental period (except when indicated), animals received standard chow with adequate values of calcium for rodents, according to the American Institute of Nutrition AIN 93 (Reeves et al. 1993).

\section{Calcium-enriched diet}

Calcium supplementation was offered from PN120 to PN180 to evaluate the effects of this micronutrient in SL rats. In order to prepare the calcium-supplemented chow in our laboratory, standard rat chow was grinded and the resulting bran was supplemented with calcium carbonate (to attain a final concentration of $10 \mathrm{~g}$ of $\mathrm{CaCO}_{3} / \mathrm{kg}$ of chow), which was mixed with the bran and water with the help of an industrial food mixer. When the mix achieved a good consistence to be pelletized, it was placed in an industrial heater $\left(60^{\circ} \mathrm{C}\right)$ for $12 \mathrm{~h}$ to dry. The supplemented chow was kept at $4^{\circ} \mathrm{C}$ until delivered to the rat cages. The same procedure was done with the chow provided to C and SL groups, except by calcium addition. The concentration of calcium used here is twice the amount recommended to rodents ( $5 \mathrm{~g} / \mathrm{kg}$ of chow) and is based on the recommendation for calcium supplementation in humans. We previously published that, at this concentration, calcium does not seem to change diet palatability since food intake, body mass, fat depot, serum leptin as well as hypothalamic leptin signaling of lean control rats are not altered by this calcium-rich diet when compared with control animals with no calcium supplementation (Nobre et al. 2011, 2012).

From PN120 to PN180, SL rats were subdivided into two groups: (1) SL group - received standard chow $(n=20)$; (2) SL-Ca group - received standard chow supplemented with calcium carbonate. The NL group $(n=20)$ received standard chow.

\section{Euthanasia and sample preparation}

Rats were anesthetized with Hypnol (pentobarbital sodium 3\%, $90 \mathrm{mg} / \mathrm{kg}$ body mass; Syntec, Brazil) and killed by exsanguination through a cardiac puncture. Blood samples collected in heparin tubes were centrifuged $\left(1500 \mathrm{~g} / 20 \mathrm{~min}\right.$ at $\left.4^{\circ} \mathrm{C}\right)$ to obtain plasma, which was kept at $-20^{\circ} \mathrm{C}$ until assay. After exsanguination, the whole brain was promptly dissected out of the cranium and immediately stored in liquid nitrogen $\left(\right.$ at $\left.-80^{\circ} \mathrm{C}\right)$, where it remained until the procedures used to analyze NPY content in the arcuate nucleus (ARC) were carried out. The entire procedure, from the beginning of the cardiac puncture to the placement of the brain in liquid nitrogen, took approximately $4 \mathrm{~min}$. In order to isolate

A
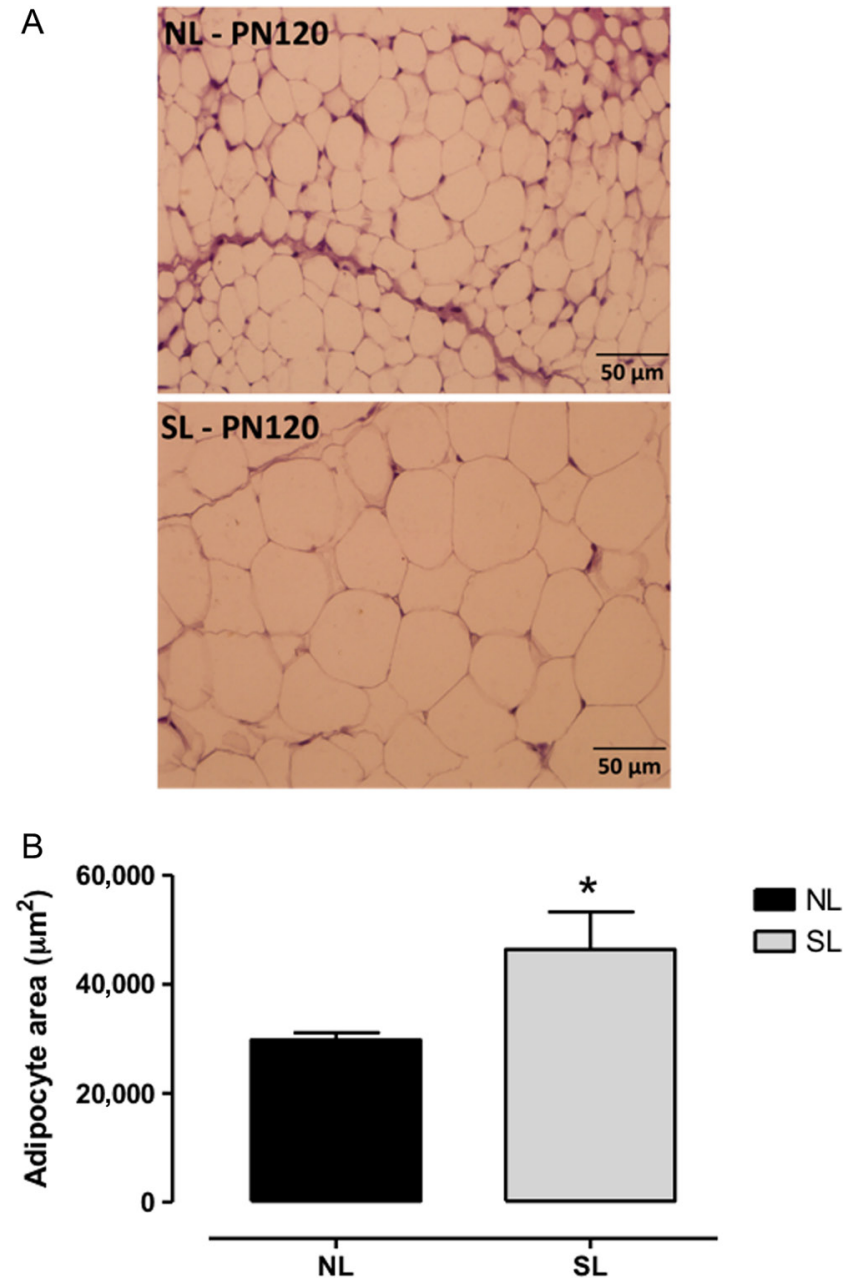

Figure 3

Effects on the visceral adipose tissue (VAT) morphology at PN120 of postnatal early overnutrition in Wistar rats. (A) Representative hematoxylin and eosin staining of epididymal adipocyte. (B) Epididymal adipocyte area is shown. NL, normal litter group; SL, small litter group. The values represent mean \pm S.E.M. of 8 rats per group. ${ }^{*} P<0.05$ vs NL.

Published by Bioscientifica Ltd 
the ARC, a coronal brain section was obtained using a cryostat following Paxinos and Watson (2007) stereotaxic atlas coordinates (ARC: bregma -1.6 to $-2.6 \mathrm{~mm}$ ). The thickness of the sections was $1500 \mu \mathrm{m}$ (2.0 mm punch diameter). The samples were kept frozen at $-80^{\circ} \mathrm{C}$ until processing by Western blotting.

\section{Hormonal determination in plasma}

Total corticosterone concentrations were determined using a radioimmunoassay commercial kit from ICN Pharmaceuticals, Inc (Orangeburg, NY, USA). The assay sensitivity was $50 \mathrm{ng} / \mathrm{mL}$. Leptin concentration was determined with an enzyme immunoassay kit for rats (EZRL-83K) following the manufacturer's instructions from LINCO Research (St. Charles, IL, USA). The minimum limit of detection was $0.04 \mathrm{ng} / \mathrm{mL}$. Total $25(\mathrm{OH}) \mathrm{D} 3$ content was evaluated by a competitive electrochemiluminescence protein binding assay from Roche Diagnostics. The measuring range was 3-70 ng/mL. All measurements were performed in one assay, and the samples were analyzed in duplicate.

\section{Morphological evaluation of the visceral adipose tissue (VAT)}

VAT samples were quickly collected and fixed in formaldehyde dissolved in phosphate-buffered saline (PBS, 0.1 M phosphate buffer, 0.9\% w/v NaCl, pH 7.4). Then, tissues were dehydrated, cleared and paraffinembedded. Nonconsecutive slices of $10 \mu \mathrm{m}$-thick sections were obtained and stained with hematoxylin/eosin. Digital images were obtained from the histological sections with an Olympus BX40 microscope (Olympus) using a $40 \times$ objective. From each rat, 3 slices were obtained and 10 photomicrographs of different fields from each slice were taken. From each photomicrograph, the area of five adipocytes was measured with the software Image-Pro Plus 5.0 from Media Cybernetics (Silver Spring, MD, USA) (Conceição et al. 2011). The researcher that performed the measurements was blind regarding group assignment.

\section{Reverse transcription polymerase chain reaction (RT-PCR) analysis}

After extraction, the VAT was stored in RNAlater solution (Thermo Fisher Scientific). The total RNA was extracted from $100 \mathrm{mg}$ VAT, under RNAse-free conditions, with TRIzol Reagent from Thermo Fisher Scientific, and DNase I (Deoxyribonuclease I, Thermo Fisher Scientific) was used
A
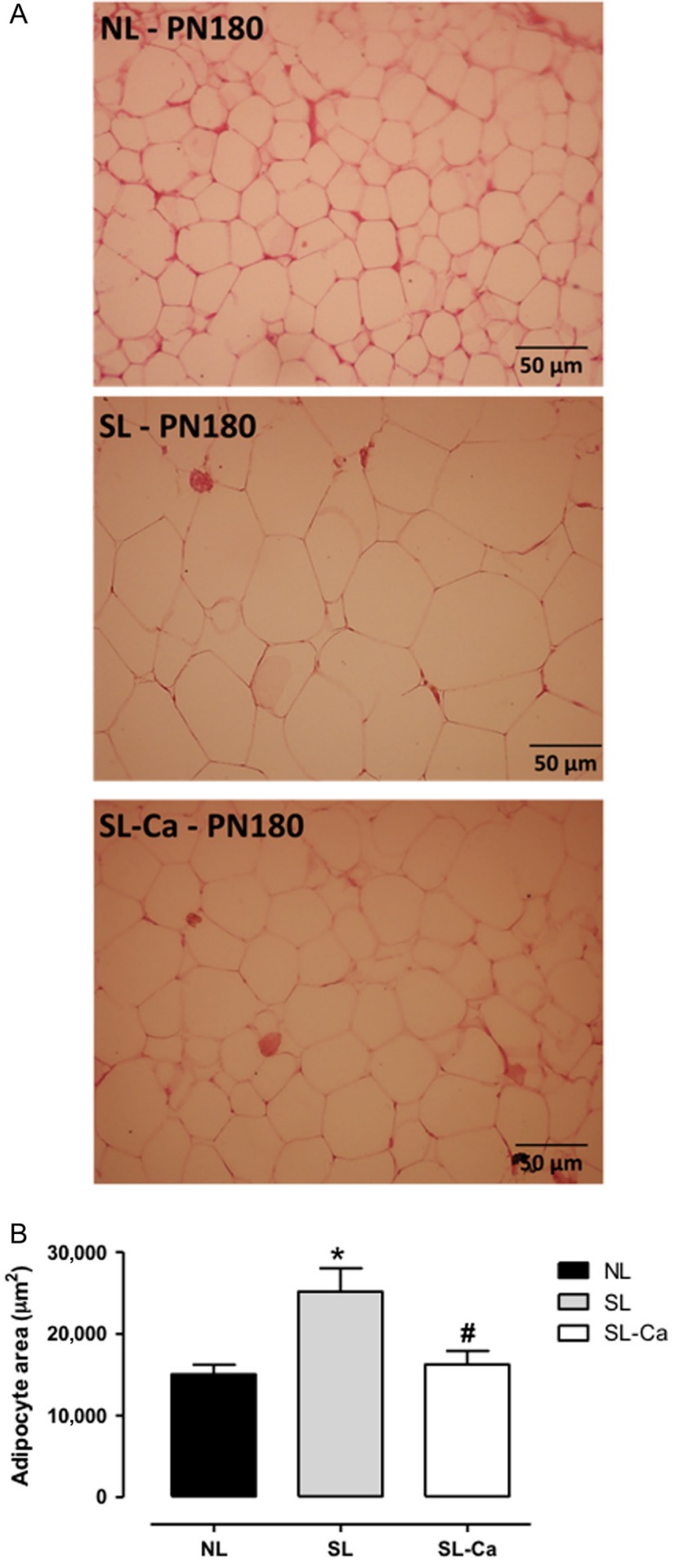

Figure 4

Effects on the visceral adipose tissue (VAT) morphology at PN180 of postnatal early overnutrition followed by 2 months of dietary calcium supplementation in Wistar rats. (A) Representative hematoxylin and eosin staining of epididymal adipocyte. (B) Epididymal adipocyte area is shown. NL, normal litter group; SL, small litter group; SL-Ca, SL group that received calcium supplementation. The values represent mean \pm S.E.M.

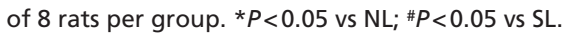

Published by Bioscientifica Ltd. 
to remove possible residues of genomic DNA. The RNA was quantified via Nano Vue Plus Spectrophotometer from GE Healthcare. The cDNA was prepared from total RNA using the Moloney Murine Leukemia Virus Reverse Transcriptase (M-MLV RT) for RT-PCR and Oligo(dT)15 Primer from Promega; in order to assure that there was no contamination with genomic DNA, a negative control was made without the addition of the reverse transcriptase, and this negative control was not amplified in RT-PCR. The mRNA levels of Cyp27b1 enzyme (primers F: 5'-TTG TAC TCC ATG CTG TCC TTG AA-3' and R: 5'-TTG TAC TCC ATG CTG TCC TTG AA-3') and of vitamin D nuclear receptor (Vdr) (primer; F: 5'-TCG TAT GGA CGG AAG TAC AGG-3' and R: 5'-CAG CAT GGA GAG AGG AGA CAG-3) in the VAT were amplified on Applied Biosystems 7500 Real-Time PCR System (Life Technologies), using SYBR Green PCR Master Mix from Applied Biosystems according to the recommendations of the manufacturer. The oligonucleotide primers and probes were designed and prepared by ABI Applied Biosystems. The coamplification of mouse 36 $\beta-4$ mRNA (primers F: 5'-TGT TTG ACA ACG GCA GCA TTT-3' and R: 5'-CCG AGG CAA CAG TTG GGT A-3), a variant internal control, was performed in all of the samples. Assays were done in triplicate and results were normalized to the $36 \beta-4$ mRNA levels using the $2^{\Delta \Delta}$ CT method (Livak \& Schmittgen 2001). The melt curves showed a single amplicon.

\section{Western blotting analysis}

Protein contents of: fatty acid synthase (FAS (ab150508, Abcam)); glucocorticoid receptor alpha (GR- $\alpha$ (sc-12763, Santa Cruz Biotechnology)); 11B-hydroxysteroid dehydrogenase type 1 (11B-HSD1 (sc-20175, Santa Cruz Biotechnology)) were evaluated by Western blotting in the VAT (epididymal fat sample); neuropeptide Y (NPY (N9525, Sigma-Aldrich)) was evaluated by Western blotting in the ARC. Briefly, tissues were homogenized on RIPA buffer $(50 \mathrm{mM}$ Tris- $\mathrm{HCl}$ (pH 7.4), 1\% NP-40, $150 \mathrm{mM} \mathrm{NaCl}$, $1 \mathrm{mM}$ EDTA, $1 \mathrm{mM}$ PMSF, $1 \mathrm{mM} \mathrm{Na} \mathrm{VO}_{4}, 1 \mathrm{mM} \mathrm{NaF}$ ) and protease inhibitor cocktail from F. Hoffmann-La Roche Ltd (Basel, Switzerland). Homogenates were centrifuged for $5 \min \left(1120 \mathrm{~g}, 4^{\circ} \mathrm{C}\right)$. Protein concentration in supernatants was determined using the Pierce BCA Protein Assay Kit from Thermo Fisher Scientific. Then, homogenates were analyzed by SDS-PAGE using $10 \mathrm{mg}$ total protein. Samples were electroblotted onto Hybond ECL nitrocellulose membranes from Amersham Pharmacia Biotech (London, UK). Membranes were incubated with Trisbuffered saline (TBS) containing $2 \%$ albumin for $90 \mathrm{~min}$.

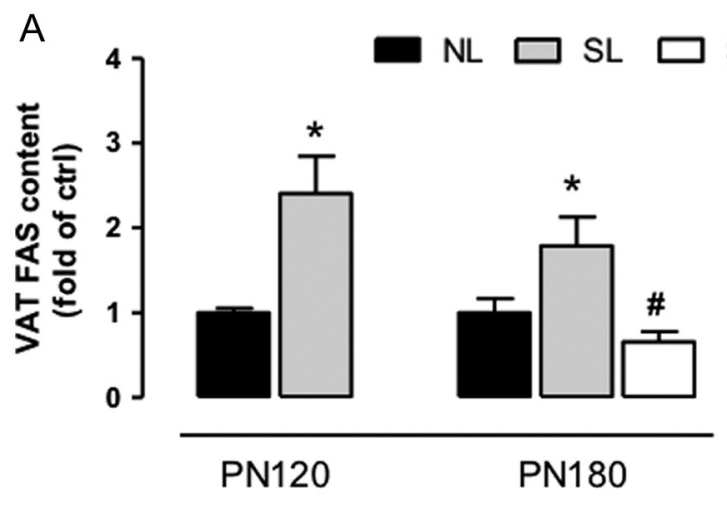

SL-Ca

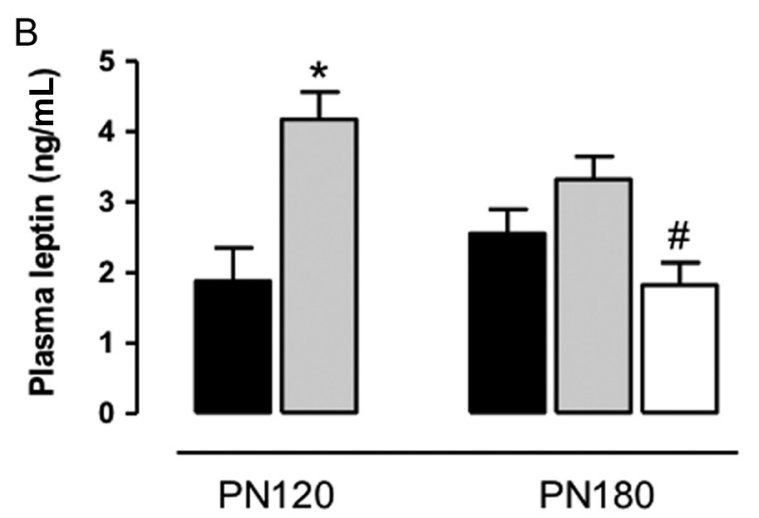

http://joe.endocrinology-journals.org DOI: 10.1530/JOE-16-0041
๑) 2016 Society for Endocrinology Printed in Great Britain

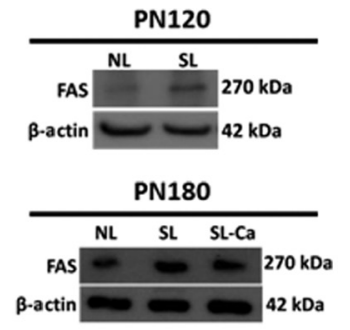

Figure 5

Effects on the visceral adipose tissue (VAT) fatty acid synthase (FAS) and plasma leptin of postnatal early overnutrition followed by 2 months of dietary calcium supplementation at adulthood in Wistar rats. (A) FAS protein content at PN120 and PN180 in the VAT. Representative blots are shown next to the graph. $\beta$-actin content was used as control loading. Results are expressed as relative (\%) to the control. (B) Leptinemia on PN120 and PN180. NL, normal litter group; SL, small litter group; SL-Ca, SL group that received calcium supplementation. The values represent mean \pm S.E.M. of 10 rats per group. ${ }^{*} P<0.05$ vs NL; ${ }^{*} P<0.05$ vs SL. 
Then, membranes were washed with TBS and incubated with a specific primary antibody (dilution 1:500) overnight at $4^{\circ} \mathrm{C}$. Membranes were washed and incubated with secondary antibody diluted to 1:5000 (antimouse, B8520 from Sigma-Aldrich; antigoat, 62-6540 and antirabbit, 65-6140 from Invitrogen) conjugated with HRP in an adequate dilution for $1 \mathrm{~h}$ at room temperature. The protein bands were visualized by chemiluminescence (Kit ECL plus, Amersham Biosciences) followed by exposure to ImageQuant LAS (GE Healthcare). Area and density of the bands were quantified by ImageJ software from Wayne Rasband National Institute of Health (Bethesda, MD, USA). Results were expressed as relative (\%) to the control group.

\section{Statistical analysis}

Data are presented as mean and standard error of the mean (s.E.M.) and differences are considered significant when $P<0.05$. When significant differences between groups are present, the relative (percentage) increase or decrease as compared with control values will be shown in parentheses along with the relevant statistical information. Results from PN120 were analyzed by Student's unpaired $t$-test (Groups: NL and SL) and results from PN180 were analyzed by one-way ANOVAs (Group (NL, SL, SL-Ca) as the between-subjects factor) followed by Newman-Keuls multiple comparisons post hoc tests. Graph Pad Prism 5.0 for Windows statistical software from GraphPad Software was used for the statistical analyses.

\section{Results}

At PN120, the SL group had higher body mass than the NL group $(+16 \% ; P<0.001)$ and, at PN180, SL and SL-Ca rats had higher body mass than NL rats (Fig. 1A). The average daily food intake showed that the SL rats were hyperphagic during their entire life, and that the calcium supplementation was able to reduce the food intake in SL-Ca rats (PN120, SL: $+158 \%$ vs NL; $P<0.001$; PN180, SL: $+77 \%$ vs NL; SL-Ca: $+16 \%$ vs NL, $-34 \%$ vs SL; $P<0.001$ for both comparisons, Fig. 1B). The SL group showed increased NPY content in the ARC both at PN120 $(+100 \%$; $P=0.039)$ and PN180 $(+50 \% ; P=0.031)$ and the SL-Ca group had values similar to controls (Fig. 1C).

As expected, at PN120 and PN180, SL rats had higher central adiposity, with heavier fat mass deposits (Fig. 2). Calcium supplementation was able to normalize the VAT mass in all depots. Figures 3 and 4 depict the
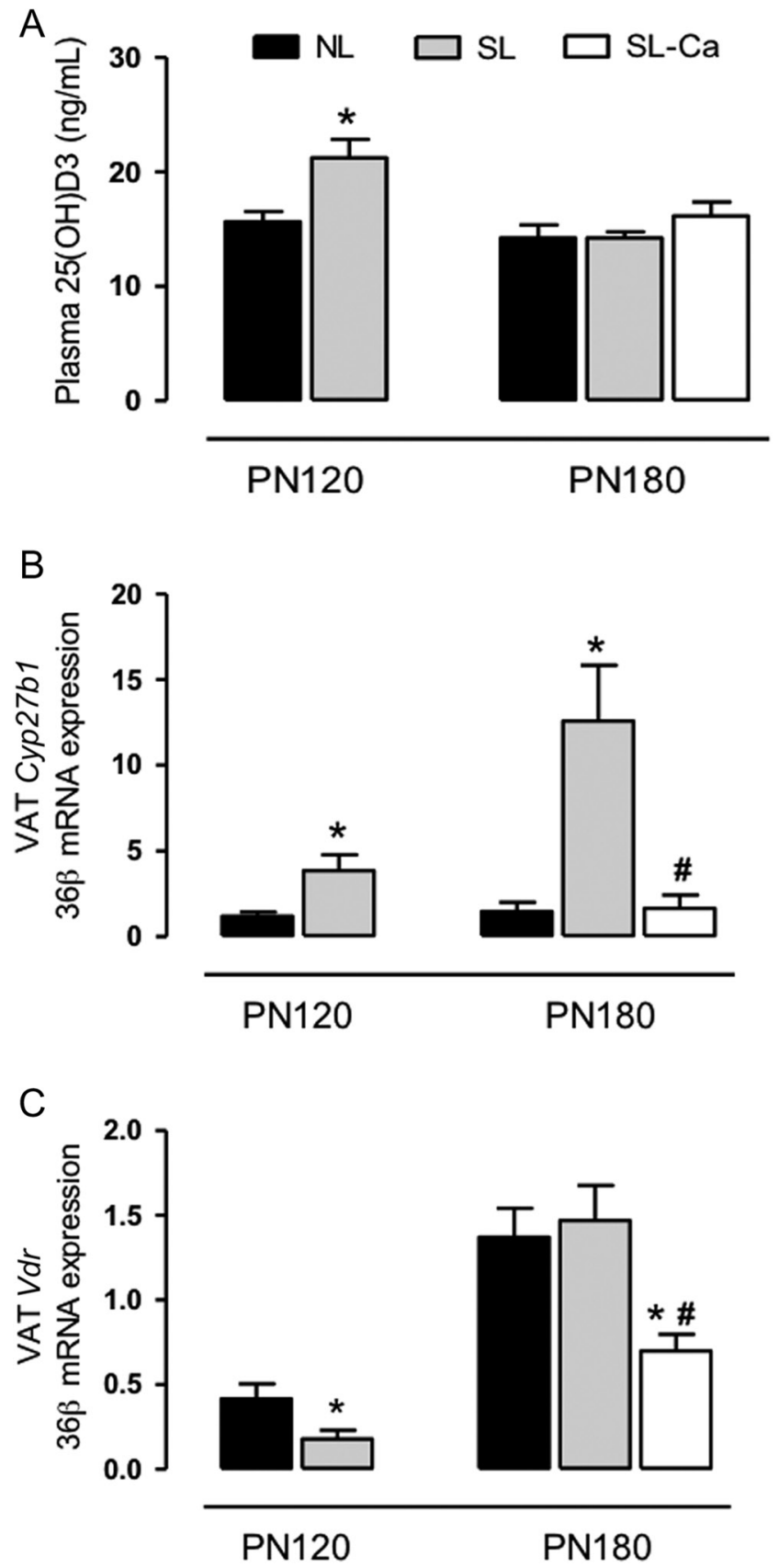

Figure 6

Effects on the vitamin $D$ status of postnatal early overnutrition followed by 2 months of dietary calcium supplementation at adulthood in Wistar rats. (A) Plasma 25(OH)D3 concentrations. (B) Visceral adipose tissue (VAT) Cyp27b1 mRNA expression. (C) VAT vitamin D receptor (Vdr) mRNA expression. Results at PN120 and PN180 are shown. NL, normal litter group; SL, small litter group; SL-Ca, SL group that received calcium supplementation. The values represent mean \pm S.E.M. of 10 rats per group. ${ }^{*} P<0.05$ vs NL; ${ }^{P} P<0.05$ vs SL.

morphology of epididymal adipocytes. SL rats had adipocyte hypertrophy compared with control ones at both PN120 ( $+56 \% ; P=0.027$, Fig. 3B) and PN180

Published by Bioscientifica Ltd 
(+67\%; $P=0.015$, Fig. 4B). Two months of calcium supplementation reverted this alteration ( $-35 \%$ vs SL; $P=0.015$, Fig. 4B).

We detected an increase in epididymal FAS protein content in the SL group at PN120 and PN180, and calcium supplementation was able to normalize its content (Fig. 5A). Plasma leptin was higher in the SL group only at PN120 (+121\%; $P=0.002$, Fig. 5B) compared with the NL group. After 60 days of dietary calcium supplementation, leptinemia returned to normal, being significantly lower than in the SL group $(-45 \% ; P=0.016)$.

Total plasma $25(\mathrm{OH}) \mathrm{D}$ concentration was higher in the SL group compared with the NL group only at PN120 (+36\% vs NL; $P=0.009$, Fig. 6A). The Cyp27b1 mRNA expression in the VAT was higher in SL rats than in NL ones at both ages (PN120: 2.3 fold-increase; PN180: 7 fold-increase; $P<0.05$ in both comparisons), and the calcium supplementation normalized this alteration ( $-87 \%$ vs SL; $P<0.001$, Fig. $6 \mathrm{~B})$. The $V d r$ mRNA expression in the VAT was lower in the SL group than in the NL group at PN120 (-57\%; P=0.03, Fig. 6C), but it was normal at PN180. The SL-Ca group had a decrease in $V d r$ mRNA expression compared with $\mathrm{NL}$ and SL groups ( -50 and $-55 \%$, respectively; $P<0.05$, in both comparisons, Fig. 6C).

The total corticosterone plasma concentration was reduced in SL-Ca rats at PN180 (-25\% vs NL; $-20 \%$ vs SL; $P<0.05$, in both comparisons, Fig. 7A). The 11B-HSD1 protein content in the VAT was not different among the groups on both ages (Fig. 7B). The glucocorticoid receptor alpha $(\mathrm{GR}-\alpha)$ protein content in the VAT was increased in the SL group at PN120 and PN180 (+87 and +67\%, respectively; $P<0.05)$. Calcium supplementation restored the GR- $\alpha$ expression ( $-60 \%$ vs SL; $P=0.012$, Fig. 7C).
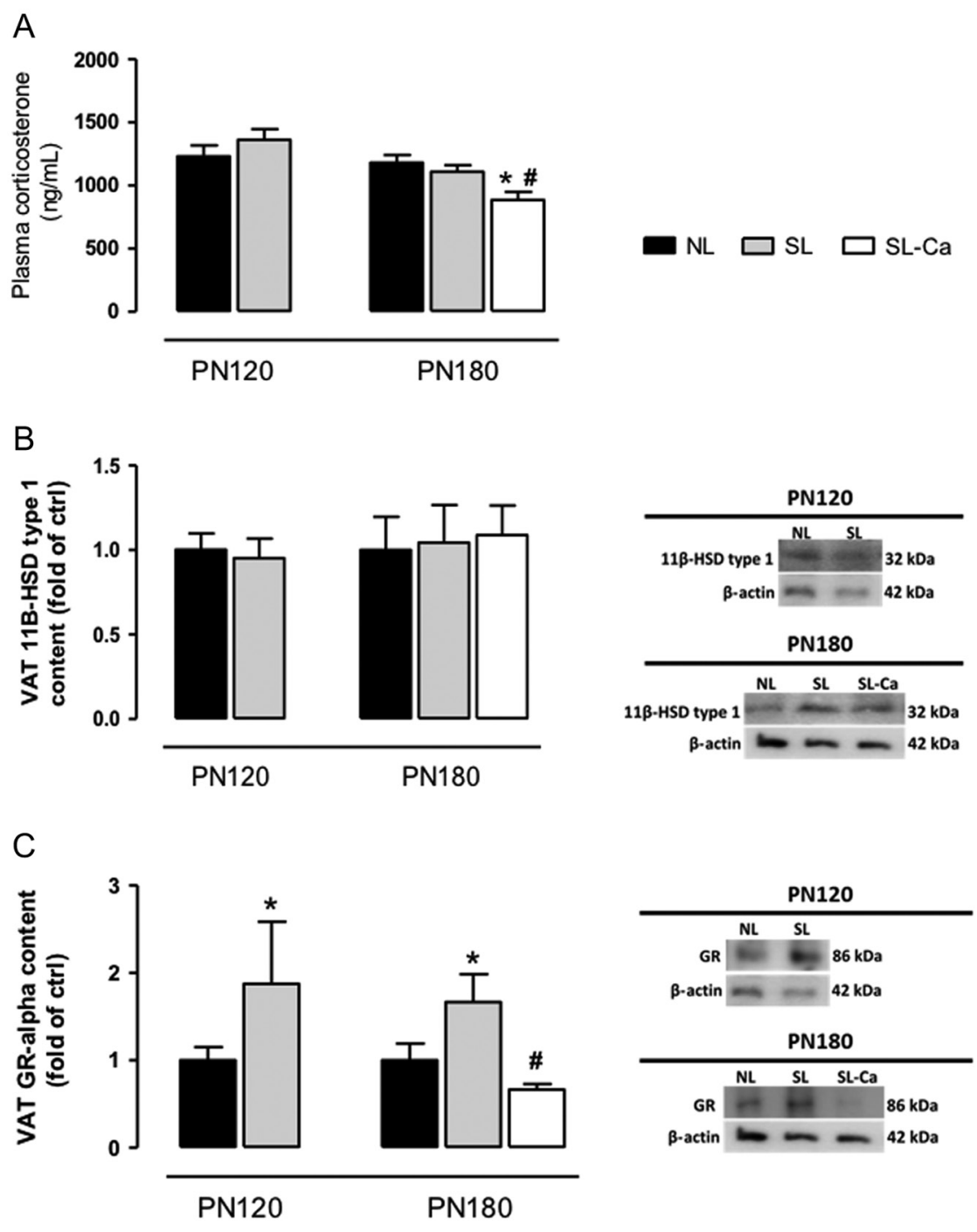

\section{Figure 7}

Effects on the glucocorticoid status of postnatal early overnutrition followed by 2 months of dietary calcium supplementation at adulthood in Wistar rats. (A) Plasma corticosterone concentrations. (B) Visceral adipose tissue (VAT) glucocorticoid receptor alpha (GR- $\alpha$ ). (C) VAT 11B-hydroxysteroid dehydrogenase type 1 (11B-HSD1). Results at PN120 and PN180 are shown. Representative blots are shown next to the graph. $\beta$-actin content was used as control loading. Results are expressed as relative (\%) to the control. NL, normal litter group; SL, small litter group; SL-Ca, SL group that received calcium supplementation. The values represent mean \pm S.E.M. of 10 rats per group. ${ }^{*} P<0.05$ vs NL; $\# P<0.05$ vs SL. 


\section{Discussion}

\section{Hormones and adipose tissue dysfunction}

As expected, SL rats had higher VAT mass and adipocyte hypertrophy in both ages. These findings are associated with high FAS content in the VAT. We have shown, for the first time, an increase in plasma $25(\mathrm{OH}) \mathrm{D}$ concentration at PN120 that was programmed by litter size reduction. At this age, the obese SL rats also had an increased Cyp27b1 mRNA in the VAT, which can contribute to the local synthesis of vitamin $\mathrm{D}$ through the activation of $25(\mathrm{OH}) \mathrm{D}$ to $1,25(\mathrm{OH})_{2} \mathrm{D}$. The $\mathrm{SL}$ group also showed a reduced $V d r$ at PN120, which can be due to a downregulation by high vitamin D levels. Our findings suggest a vitamin D resistance in adipocytes at PN120 that may be associated with the fat accumulation in SL rats. In another obesity model, we also found, in adult rats, higher $C y p 27 b 1$ and lower $V d r$ in the VAT, with higher $\mathrm{C} / \mathrm{EBP} \beta$ and PPAR $\gamma$ expression in the adipose tissue, which could be a key factor in obesogenesis (Nobre et al. 2016).

Interestingly, at PN180, obese SL rats did not show the same pattern observed at PN120, since they exhibited normal plasma 25(OH)D and VAT $V d r$, although the Cyp27b1 mRNA was still increased. This is puzzling, since we expected a downregulation of VDR due to the higher intracellular vitamin D conversion, as explained for PN120. However, plasma vitamin D was normal at PN180. Therefore, even with the higher conversion rates, it is conceivable that the amount of $1,25(\mathrm{OH})_{2} \mathrm{D}$ was not enough to downregulate VDR. Another possible explanation is that, with aging and obesity, the adipocytes of SL rats are more dysfunctional at PN180, losing the physiological downregulation mechanism for vitamin D.

At PN120, SL rats had increased plasma leptin, which was expected since the positive correlation between adiposity and leptinemia is well known (Fain et al. 2004, Knight et al. 2010). In addition, the hyperphagia of SL rats can be explained by both the leptin resistance (Rodrigues et al. 2009, 2011, Zhang et al. 2011) and the higher NPY in the ARC. Previously, Plagemann and coworkers (1999) have shown that SL rats have higher NPY-immunopositive neurons at weaning, explaining their higher food intake since weaning.

Besides the influence of vitamin D on adipogenesis, this hormone also induces leptin production (Kong et al. 2013). Previous reports have shown that leptin is able to decrease the gene expression of 1- $\alpha$-hydroxylase in the mice renal proximal tubules (Matsunuma \& Horiuchi 2007). This suggest that $1,25(\mathrm{OH})_{2} \mathrm{D}$ stimulates a negative feedback through leptin action, inhibiting vitamin D production. However, in the adipose tissue of SL rats, $C y p 27 b 1$ in the VAT is higher despite the hyperleptinemia. This suggests a leptin resistance at the adipocyte level. However, we did not evaluate the leptin signaling pathway in the adipocyte, but we have shown, in a different obesity model, that the adipose tissue had leptin resistance (with lower Ob-R expression) and higher CYP27B1 (Nobre et al. 2016). In fact, normal 25(OH)D with increased $1,25(\mathrm{OH}) 2 \mathrm{D}$ levels in obese rats have already been reported in a diet-induced obesity (DIO) model by Park and coworkers (2015).

At PN180, SL rats had unchanged leptinemia, despite having a higher VAT, corroborating a previous report (Conceição et al. 2011). In this study, we have also shown a lower leptin production, evidencing that with aging, the adipocytes become dysfunctional and release less leptin. In fact, in patients, it has already been reported that leptin production is inversely related to the severity of the metabolic syndrome (Paz-Filho et al. 2009). In the same way, aging seems to affect the plasma $25(\mathrm{OH}) \mathrm{D}$ in SL rats, which was higher at PN120 and became normal at PN180. One possibility is that, with aging, the adipocyte sequesters more vitamin D.

In addition, glucocorticoids (GCs) are another important regulator of lipid accumulation, stimulating adipocyte differentiation and fat distribution. It is known that alterations in central and peripheral GC production and sensitivity are common in obese human and animal models of obesity (Yu et al. 2014, Manolopoulos et al. 2015). Here, SL rats did not display changes in plasma corticosterone or its metabolism (11B-HSD1) in the adipose tissue at both ages. However, an increase in GR- $\alpha$ protein content in the VAT was detected in SL rats at PN120 and PN180, suggestive of higher corticosterone sensitivity, which could contribute to the fat accumulation in these animals.

\section{Effect of calcium-enriched diet}

The current study evidence that dietary calcium supplementation during 2 months at adulthood reduces food intake and normalizes central adiposity in SL rats. Two mechanisms may help to explain the reduction of fat depots in our study: (1) calcium supplementation increases fecal fat excretion (Denke et al. 1993, Shahkhalili et al. 2001, Jacobsen et al. 2005); (2) calcium supplementation decreased CEBP/ $\beta$ and PPAR $\gamma$ expression, 
two proadipogenic and lipogenic biomarkers, in the VAT of early-weaned rats (Nobre et al. 2016).

Gonzalez and coworkers (2015) have shown that calcium supplementation in humans reduces postprandial appetite sensation. Previously, our group has demonstrated that calcium supplementation is able to reduce hyperphagia in obese adult rats that were early-weaned through the improvement of the leptin signaling in the hypothalamus (Nobre et al. 2012) and of the glucagon-like peptide 1 response (Quitete et al. 2015). Here, we detected that the increased NPY content in the ARC of SL animals was normalized by dietary calcium supplementation. We have also shown that the SL-Ca group had hypoleptinemia, which suggests that leptin resistance was corrected by calcium supplementation.

In this study, calcium supplementation did not alter the 25(OH)D level, but caused an impact on the vitamin D metabolism and its receptor in the adipocytes of obese SL rats, possibly contributing to the correction of adipocyte dysfunction, since SL-Ca rats had normal Cyp27b1 mRNA level and decreased $V d r$ mRNA in the VAT. According to Sun and Zemel (2007), a high calcium diet inhibits the adipocyte production of $1-\alpha-25(\mathrm{OH}) \mathrm{D}$, favoring the VAT mass loss. Since leptin and vitamin D suppress the expression of this enzyme (Matsunuma \& Horiuchi 2007, Adams \& Hewison 2010), the normal levels of 1- $\alpha-25(\mathrm{OH}) \mathrm{D}$ in SL-Ca group can be related to the restoration of both leptin and vitamin D sensitivity in this tissue, consequently favoring the VAT reduction. After calcium supplementation, the observed lower $V d r$ mRNA could be the result of a lower GC effect in adipocyte since this hormone stimulates $V d r$ expression (Sun \& Zemel 2008, Hidalgo et al. 2010).

We cannot discard, at this point, the possibility that another nonvitamin D-related mechanism is responsible for the reduced adiposity that occurs after calcium supplementation. For instance, PTH affects the adipocyte function, increasing lipolysis in mice (Larsson et al. 2016) and suppressing insulin signaling in 3T3-L1 adipocytes (Chang et al. 2009).

The SL-Ca group had a reduction in corticosteronemia and in its receptor content in the adipocyte, which may favor the VAT decrease. Thus, the correction of corticosterone sensitivity in the adipocyte can be another mechanism induced by calcium that helps to explain its antiobesogenic effect in the SL model. One limitation of this study is the fact that we did not evaluate 11B-HSD in the liver, since calcium could have a tissue-specific effect on this enzyme. Also, we did not evaluate how dietary calcium could affect the hypothalamic-pituitary-adrenal cortex.
The hormonal endpoints (vitamin D and glucocorticoids) in the VAT after calcium supplementation could be secondary to the reduced visceral fat mass, since the SL-Ca group had reduced food intake and it is well known that high calcium intake is associated with the decrease in meal fat content absorption (Tremblay \& Gilbert 2011). A time-course study in which we evaluate these hormonal endpoints before calcium reduces adiposity would help clarify whether the changes in GC and vitamin D metabolism and receptors precede the changes in adiposity, supporting our suggestion of a mechanistic role for these hormones in the obesogenesis of this experimental model. An evaluation of the enzymatic activity could also confirm the results found here, which are shown only by mRNA or protein expression.

Here, we have shown that both vitamin D and GC metabolism in the adipocyte is altered in adult obese rats that were early overfed during lactation, which was associated with increased visceral adiposity. Taken together, the present data suggest that vitamin D resistance at the adipocyte level as well as an elevation of GC action in the adipose tissue could be involved in the obese phenotype of the SL model. Besides, the calciumenriched diet was successful in reducing abdominal fat deposits, possibly by decreasing food consumption and by normalizing both vitamin D and GC function the adipocyte.

\section{Declaration of interest}

The authors declare that there is no competing interest that could be perceived as prejudicing the impartiality of the reported research.

\section{Funding}

This research was supported by the 'National Council for Scientific and Technological Development' (Conselho Nacional de Desenvolvimento Científico e Tecnológico-(NPq) and the 'Carlos Chagas Filho Research Foundation of the State of Rio de Janeiro' (Fundação Carlos Chagas Filho de Amparo à Pesquisa do Estado do Rio de Janeiro-FAPERJ). E P S C and $J \mathrm{~L} N$ were recipients of a FAPERJ fellowship and $J \mathrm{C} C$ was recipient of a CNPq fellowship.

\section{Author contribution statement}

Concept and design: E P S C, E G M, E O and P C L; Animal treatment, collection of samples and measurements: E P S C, J C C and J L N; Analysis and interpretation of data: E P S C, E G M, J C C, J L N, E O and P C L; Drafting and/or revising the article critically for important intellectual content: E P S C, E G M, A C M, E O and P C L.

\section{Acknowledgements}

All the authors are grateful to Miss Monica Moura and Ulisses Risso for technical assistance.

Published by Bioscientifica Ltd. 


\section{References}

Adams JS \& Hewison M 2010 Update in vitamin D. Journal of Clinical Endocrinology and Metabolism 95 471-478. (doi:10.1210/jc.2009-1773)

Akbaraly TN, Kivimaki M, Ancelin ML, Barberger-Gateau P, Mura T, Tzourio C, Touchon J, Ritchie K \& Berr C 2010 Metabolic syndrome, its components, and mortality in the elderly. Journal of Clinical Endocrinology and Metabolism 95 E327-E332. (doi:10.1210/ jc.2010-0153)

Blumberg JM, Tzameli I, Astapova I, Lam FS, Flier JS \& Hollenberg AN 2006 Complex role of the vitamin D receptor and its ligand in adipogenesis in 3T3-L1cells. Journal of Biological Chemistry $\mathbf{2 8 1}$ 11205-11213. (doi:10.1074/jbc.M510343200)

Briot K, Audran M, Cortet B, Fardellone P, Marcelli C, Orcel P, Vellas B, Thomas T \& Roux C 2009 Vitamin D: skeletal and extra skeletal effects; recommendations for good practice. Presse Médicale 38 43-54. (doi:10.1016/j.lpm.2008.08.008)

Chang E, Donkin SS \& Teegarden D 2009 Parathyroid hormone suppresses insulin signaling in adipocytes. Molecular and Cellular Endocrinology 307 77-82. (doi:10.1016/j.mce.2009.03.024)

Conceição EP, Trevenzoli IH, Oliveira E, Franco JG, Carlos AS, Nascimento-Saba CC, Moura EG \& Lisboa PC 2011 Higher white adipocyte area and lower leptin production in adult rats overfed during lactation. Hormone and Metabolic Research 43 513-516. (doi:10.1055/s-0031-1275702)

Conceição EP, Franco JG, Oliveira E, Resende AC, Amaral TA, Peixoto-Silva N, Passos MC, Moura EG \& Lisboa PC 2013 Oxidative stress programming in a rat model of postnatal early overnutrition role of insulin resistance. Journal of Nutritional Biochemistry 24 81-87. (doi:10.1016/j.jnutbio.2012.02.010)

Cornier MA, Dabelea D, Hernandez TL, Lindstrom RC, Steig AJ, Stob NR, Van Pelt RE, Wang H \& Eckel RH 2008 The metabolic syndrome. Endocrine Reviews 29 777-822. (doi:10.1210/er.2008-0024)

Crane MM, Lutes LD, Ward DS, Bowling JM \& Tate DF 2015 A randomized trial testing the efficacy of a novel approach to weight loss among men with overweight and obesity. Obesity 23 2398-2405. (doi:10.1002/oby.21265)

de Albuquerque Maia L, Lisboa PC, de Oliveira E, da Conceição EP, Lima IC, Lopes RT, Ruffoni LD, Nonaka KO \& de Moura EG 2014 Bone structure and strength are enhanced in rats programmed by early overfeeding. Hormone and Metabolic Research 46 259-268. (doi:10.1055/s-00000025)

de Guia RM \& Herzig S 2015 How do glucocorticoids regulate lipid metabolism? Advances in Experimental Medicine and Biology 872 127-144. (doi:10.1007/978-1-4939-2895-8)

Denke MA, Fox MM \& Schulte MC 1993 Short-term dietary calcium fortification increases fecal saturated fat content and reduces serum lipids in men. Journal of Nutrition 123 1047-1053.

Fain JN, Madan AK, Hiler ML, Cheema P \& Bahouth SW 2004 Comparison of the release of adipokines by adipose tissue, adipose tissue matrix, and adipocytes from visceral and subcutaneous abdominal adipose tissues of obese humans. Endocrinology 145 2273-2282. (doi:10.1210/en.2003-1336)

Finkelstein EA 2014 How big of a problem is obesity? Surgery for Obesity and Related Diseases 10 569-750. (doi:10.1016/j.soard.2014.02.028)

Ghali O, Broux O, Falgayrac G, Haren N, van Leeuwen JP, Penel G, Hardouin P \& Chauveau C 2015 Dexamethasone in osteogenic medium strongly induces adipocyte differentiation of mouse bone marrow stromal cells and increases osteoblast differentiation. BMC Cell Biology 16 19. (doi:10.1186/s12860-015-0056-6)

Glendenning P 2015 Measuring vitamin D. Australian Prescriber 38 12-15. (doi:10.18773/austprescr.2015.004)

Gonzalez JT, Green BP, Brown MA, Rumbold PL, Turner LA \& Stevenson EJ 2015 Calcium ingestion suppresses appetite and produces acute overcompensation of energy intake independent of protein in healthy adults. Journal of Nutrition 145 476-482. (doi:10.3945/jn.114.205708)

Habbout A, Li N, Rochette L \& Vergely C 2013 Postnatal overfeeding in rodents by litter size reduction induces major short- and long-term pathophysiological consequences. Journal of Nutrition 143 553-562. (doi:10.3945/jn.112.172825)

Hidalgo AA, Trump DL \& Johnson CS 2010 Glucocorticoid regulation of the vitamin D receptor. Journal of Steroid Biochemistry and Molecular Biology 121 372-375. (doi:10.1016/j.jsbmb.2010.03.081)

Holick MF 2009 Vitamin D status: measurement, interpretation, and clinical application. Annals of Epidemiology 19 73-78. (doi:10.1016/ j.annepidem.2007.12.001)

Jacobsen R, Lorenzen J, Toubro S, Krog-Mikkelsen I \& Astrup A 2005 Effect of short- term high dietary calcium intake on 24-h energy expenditure, fat oxidation, and fecal fat excretion. International Journal of Obesity 29 292-301. (doi:10.1038/sj.ijo.0802785)

John K, Marino JS, Sanchez ER \& Hinds TD Jr 2016 The glucocorticoid receptor: cause or cure for obesity? American Journal of Physiology: Endocrinology and Metabolism 310 E249-E257. (doi:10.1152/ ajpendo.00478.2015)

Knight ZA, Hannan KS, Greenberg ML \& Friedman JM 2010 Hyperleptinemia is required for the development of leptin resistance. PLOS ONE 5 e11376. (doi:10.1371/journal.pone.0011376)

Kong J \& Li YC 2006 Molecular mechanism of 1,25-dihydroxyvitaminD3 inhibition of adipogenesis in 3T3-L1cells. American Journal of Physiology: Endocrinology and Metabolism 290 E916-E924. (doi:10.1152/ajpendo.00410.2005)

Kong J, Chen Y, Zhu G, Zhao Q \& Li YC 2013 1,25-Dihydroxyvitamin D3 upregulates leptin expression in mouse adipose tissue. Journal of Endocrinology 216 265-271. (doi:10.1530/JOE-12-0344)

Larsson S, Jones HA, Göransson O, Degerman E \& Holm C 2016 Parathyroid hormone induces adipocyte lipolysis via PKA-mediated phosphorylation of hormone-sensitive lipase. Cellular Signalling 28 204-213. (doi:10.1016/j.cellsig.2015.12.012)

Livak KJ \& Schmittgen TD 2001 Analysis of relative gene expression data using real-time quantitative PCR and the 2(-Delta Delta C(T)) method. Methods 25 402-408. (doi:10.1006/meth.2001.1262)

Malloy PJ \& Feldman BJ 2013 Cell-autonomous regulation of brown fat identity gene UCP1 by unliganded vitamin D receptor. Molecular Endocrinology 27 1632-1642. (doi:10.1210/me.2013-1037)

Maksimov ML, Svistunov AA, Tarasov VV, Chubarev VN, Ávila-Rodriguez M, Barreto GE, Dralova OV \& Aliev G 2016 Approaches for the development of drugs for treatment of obesity and metabolic syndrome. Current Pharmaceutical Design 22 895-903. (doi:10.2174/1381612822666151209153047)

Manolopoulos K, Thornhill H, Thomas J, Arlt W \& Tomlinson J 2015 Association between hypercortisolaemia and adipose tissue blood flow in vivo. Lancet 26 S63. (doi:10.1016/S0140-6736(15)60378-6)

Marotte C, Bryk G, Gonzales Chaves MM, Lifshitz F, de Portela ML \& Zeni SN 2014 Low dietary calcium and obesity: a comparative study in genetically obese and normal rats during early growth. European Journal of Nutrition $\mathbf{5 3}$ 769-778. (doi:10.1007/s00394013-0581-z)

Matsunuma A \& Horiuchi N 2007 Leptin attenuates gene expression for renal 25-hydroxyvitamin D3-1alpha-hydroxylase in mice via the long form of the leptin receptor. Archives of Biochemistry and Biophysics $\mathbf{1}$ 118-127. (doi:10.1016/j.abb.2007.02.031)

Nobre JL, Lisboa PC, Santos-Silva AP, Lima NS, Manhães AC, Nogueira-Neto JF, Cabanelas A, Pazos-Moura CC, Moura EG \& de Oliveira E 2011 Calcium supplementation reverts central adiposity, leptin, and insulin resistance in adult offspring programed by neonatal nicotine exposure. Journal of Endocrinology 210 349-359. (doi:10.1530/JOE-11-0172)

Nobre JL, Lisboa PC, Lima Nda S, Franco JG, Nogueira Neto JF, de Moura EG \& de Oliveira E 2012 Calcium supplementation prevents obesity, hyperleptinaemia and hyperglycaemia in adult http://joe.endocrinology-journals.org

DOI: 10.1530/JOE-16-0041
๑ 2016 Society for Endocrinology Printed in Great Britain 
rats programmed by early weaning. British Journal of Nutrition $\mathbf{1 0 7}$ 979-988. (doi:10.1017/S0007114511003928)

Nobre JL, Lisboa PC, Peixoto-Silva N, Quitete FT, Carvalho JC, de Moura EG \& de Oliveira E 2016 Role of vitamin D in adipose tissue in obese rats programmed by early weaning and post diet calcium. Molecular Nutrition and Food Research 60 810-822. (doi:10.1002/ mnfr.201500735)

Omdahl JL, Morris HA \& May BK 2002 Hydroxylase enzymes of the vitamin D pathway: expression, function, and regulation. Annual Review of Nutrition 22 139-166. (doi:10.1146/annurev. nutr.22.120501.150216)

Park JM, Park CY \& Han SN 2015 High fat diet-induced obesity alters vitamin D metabolizing enzyme expression in mice. BioFactors 41 175-182. (doi:10.1002/biof.1211)

Paxinos G \& Watson C 2007 The Rat Brain in Stereotaxic Coordinates, edn 6. Amsterdam, The Netherlands: Elsevier.

Paz-Filho GJ, Volaco A, Suplicy HL, Radominski RB \& Boguszewski CL 2009 Decrease in leptin production by the adipose tissue in obesity associated with severe metabolic syndrome. Arquivos Brasileiros de Endocrinologia \& Metabologia 53 1088-1095. (doi:10.1590/S000427302009000900005)

Plagemann A, Harder T, Rake A, Waas T, Melchior K, Ziska T, Rohde W \& Dörner G 1999 Observations on the orexigenic hypothalamic neuropeptide Y-system in neonatally overfed weanling rats. Journal of Neuroendocrinology 11 541-546.

Quitete FT, Nobre JL, Peixoto-Silva N, de Moura EG, Lisboa PC \& de Oliveira E 2015 Anti-obesogenic effects of calcium prevent changes in the GLP-1 profile in adult rats primed by early weaning. Molecular Nutrition \& Food Research 59 773-783. (doi:10.1002/ mnfr.201400666)

Reeves PG, Nielsen FH \& Fahey GC Jr 1993 AIN-93 purified diets for laboratory rodents: final report of the American Institute of Nutrition ad hoc writing committee on the reformulation of the AIN-76A rodent diet. Journal of Nutrition 11 1939-1951.

Rodrigues AL, De Souza EP, Da Silva SV, Rodrigues DS, Nascimento AB, Barja-Fidalgo C \& De Freitas MS 2007 Low expression of insulin signaling molecules impairs glucose uptake in adipocytes after early overnutrition. Journal of Endocrinology 195 485-494. (doi:10.1677/ JOE-07-0046)

Rodrigues AL, de Moura EG, Passos MC, Dutra SC \& Lisboa PC 2009 Postnatal early overnutrition changes the leptin signaling pathway in the hypothalamic-pituitary-thyroid axis of young and adult rats. Journal of Physiology 1 2647-2661. (doi:10.1113/jphysiol.2009.169045)

Rodrigues AL, de Moura EG, Passos MC, Trevenzoli IH, da Conceição EP, Bonono IT, Neto JF \& Lisboa PC 2011 Postnatal early overfeeding induces hypothalamic higher SOCS3 expression and lower STAT3 activity in adult rats. Journal of Nutritional Biochemistry 22 109-117. (doi:10.1016/j.jnutbio.2009.11.013)
Rosenstreich SJ, Rich C \& Volwiler W 1971 Deposition in and release of vitamin D3 from body fat: evidence for a storage site in the rat. Journal of Clinical Investigation 50 679-687. (doi:10.1172/JCI106538)

Shahkhalili Y, Murset C, Meirim I, Duruz E, Guinchard S, Cavadini C \& Acheson K 2001 Calcium supplementation of chocolate: effect on cocoa butter digestibility and blood lipids in humans. American Journal of Clinical Nutrition 73 246-252.

Shannan B, Seifert M, Boothman DA, Tilgen W \& Reichrath J 2007 Clusterin over-expression modulates proapoptotic and antiproliferative effects of 1,25(OH)2D3 in prostate cancer cells in vitro. Journal of Steroid Biochemistry and Molecular Biology 103 721-725. (doi:10.1016/j.jsbmb.2006.12.068)

Shi H, Norman AW, Okamura WH, Sen A \& Zemel MB 2001 1alpha,25Dihydroxyvitamin D3 modulates human adipocyte metabolism via nongenomic action. FASEB Journal 15 2751-2753. (doi:10.1096/fj.010584fje)

Souberbielle JC, Deschenes G, Fouque D, Groussin L, Guggenbuhl P, Jean G, Linglart A \& Thomas T 2016 Recommendations for the measurement of blood 25-OH vitamin D. Annales de Biologie Clinique 74 7-19. (doi:10.1684/abc.2015.1107)

Sun X \& Zemel MB 2007 Calcium and 1,25-dihydroxyvitamin D3 regulation of adipokine expression. Obesity 15 340-348. (doi:10.1038/oby.2007.540)

Sun X \& Zemel MB 2008 1Alpha, 25-dihydroxyvitamin D and corticosteroid regulate adipocyte nuclear vitamin $\mathrm{D}$ receptor. International Journal of Obesity 32 1305-1311. (doi:10.1038/ ijo.2008.59)

Tremblay A \& Gilbert JA 2011 Human obesity: is insufficient calcium/dairy intake part of the problem? Journal of the American College of Nutrition 5 (Supplement 1) 449S-453S.

Yao Y, Zhu L, He L, Duan Y, Liang W, Nie Z, Jin Y, Wu X \& Fang Y 2015 A meta-analysis of the relationship between vitamin $\mathrm{D}$ deficiency and obesity. International Journal of Clinical and Experimental Medicine $\mathbf{1 5}$ 14977-14984.

Yu J, Yu B, He J, Zheng P, Mao X, Han G \& Chen D 2014 Chronic glucocorticoid exposure-induced epididymal adiposity is associated with mitochondrial dysfunction in white adipose tissue of male C57BL/6J mice. PLoS ONE 12 e112628. (doi:10.1371/journal. pone.0112628)

Zhang XY, Zhang Q \& Wang DH 2011 Litter size variation in hypothalamic gene expression determines adult metabolic phenotype in Brandt's voles (Lasiopodomys brandtii). PLOS ONE 6 e19913. (doi:10.1371/journal.pone.0019913)

Zhang Y, Leung DY \& Goleva E 2014 Anti-inflammatory and corticosteroid-enhancing actions of vitamin $\mathrm{D}$ in monocytes of patients with steroid-resistant and those with steroid-sensitive asthma. Journal of Allergy and Clinical Immunology 133 1744-1752. (doi:10.1016/j.jaci.2013.12.004)

Received in final form 26 May 2016

Accepted 20 June 2016

Accepted Preprint published online 20 June 2016 http://joe.endocrinology-journals.org

DOI: $10.1530 / J O E-16-0041$
() 2016 Society for Endocrinology Printed in Great Britain
Published by Bioscientifica Ltd. 